\title{
Nutritional evaluation, antioxidant studies and quantification of poly phenolics, in Roscoea purpurea tubers
}

\author{
Ankita Misra, Sharad Srivastava*, Shikhar Verma and Ajay Kumar Singh Rawat
}

\begin{abstract}
Background: Roscoea purpurea (Zingiberaceae) is commonly known as "kakoli". Traditionally, various parts like leaves, roots and flower etc. are used for the treatment of diabetic, hypertension, diarrhea, fever, inflammation etc. In Nepal tubers are boiled for edible purpose and also used in traditional veterinary medicine. The study aims for nutritional characterization, chemical profiling of $R$. purpurea (tubers) methanol extract (RPE) along with evaluation of its anti-oxidant activity. Physicochemical and nutritional content were estimated as per standard protocols. Chemical profiling of markers includes method optimization, identification \& quantification of bioactive poly phenolics through HPTLC. Anti oxidant potential RPE was analyzed via. Total phenolics (TPC), total flavonoids (TFC), reducing power assay, DPPH and $\beta$-carotene bleaching model.

Results: Physicochemical and nutritional standards were established. Kaempferol (0.30\%), vanillic acid (0.27\%), protocatechuic $(0.14 \%)$, syringic $(0.80 \%)$ and ferulic acid $(0.05 \%)$ were identified and then quantified. TPC and TFC content were found to be $7.10 \pm 0.115$ and $6.10 \pm 0.055 \%$, reducing power of extract also increases linearly $\left(r^{2}=0.946\right)$ with concentration, similar to standards. $I C_{50}$ value of extract in DPPH and $\beta$-carotene bleaching model was observed at $810.66 \pm 1.154$ and $600.66 \pm 1.154 \mu \mathrm{g} / \mathrm{ml}$, which is significantly different from standards $(p<0.05)$. Although there is a positive, significant correlation between the phenolic and flavonoid content with anti oxidant activity of extract.
\end{abstract}

Conclusion: Thus, study will authenticates the identity, utility of herb as nutrient supplement and an important medicinal plant having promising pharmacological activities for further elaborated/extended investigation work.

Keywords: Roscoea purpurea, Nutritional characterization, HPTLC, Invitro assays, Poly phenolics

\section{Background}

Roscoea purpurea synonymously known as Roscoea procera (Wall.) is a perennial herb belonging to family Zingiberaceae. The specie is locally renowned as kakoli, red gukhra, dhawanksholika, karnika, ksheera, madhura, shukla, svadumansi, vayasoli and vaysasha etc. and is native of Nepal. $R$. purpurea is abundantly available in Himalayas also; on steep, grassy hill sides, damp gullies and stony slopes. Like all members of the genus Roscoea, it dies back each year to short vertical rhizomes which are attached to the tuberous roots; the most utilized part. When growth begins again, "pseudo stems" are

*Correspondence: sharad_ks2003@yahoo.com

Pharmacognosy and Ethanopharmacology Division, CSIR-National

Botanical Research Institute, Lucknow 226001, India produced: structures which resemble stems but are actually formed from the tightly wrapped bases (sheaths) of its leaves. $R$. purpurea can grow to over $50 \mathrm{~cm}$ tall, with wide leaves and a stout pseudo-stem. The leaf sheaths are pale green or may have a dark reddish-purple tinge. $R$. purpurea is cultivated as an ornamental plant, although in northern India fleshy roots are traditionally used for making a tonic to treat malaria and urinary infection. In ethnobotanical practice, the various plants parts like leaves, roots and flower etc. are used for the treatment of diabetic, hypertension, diarrhea, fever, inflammation etc. In Nepal tubers are boiled for edible purpose and also used in traditional veterinary medicine $[1,2]$. Tubers of Roscoea are major constituent of polyherbal Ayurvedic formulation, "Ashtavarga", which according to Nikhandu 
Samhita and Indian Metria Medica is like chawanprash having, anti-oxidant, anti ageing effect and elevates overall health status of a well being [3].

Tubers of $R$. purpurea exhibit immuno-modulatory [4] and antidiabetic activity [5]. Botanical studies on tubers showed the presence of 10-12 layered cork, below the cork phellogen layer is present; cortex consisting of oval to elongated, thin walled, parenchymatous cells filled with abundant, simple, ovoid to ellipsoidal starch grains, followed to vascular bundles composed of usual elements [6]. Inspite of all this available literature, there exist a lot of confusion regarding the authenticity and identity of species and the concrete data on physico-chemical characterization, chemical profiling and nutritional potential is still lacking. Till date no work has yet been carried out on identification and quantification of phenolics in species, neither the antioxidant nor antimicrobial potential of tuber had been evaluated. Hence in the present study an attempt was made with the objectives, to identify the various physico-chemical standards of the species, to validate the edible use of $R$. purpurea tuber through quantification of its nutritional contents, chemical profiling, quantification and method optimization for identification of bioactive polyphenolics and evaluation of its anti oxidant potential.

\section{Methods}

\section{Reagents}

Ascorbic acid (>97\%), quercetin (>97\%), rutin (>99\%), BHT (Butylated hydroxy toluene, >98\%), 1-1-diphenyl2-pic-rylhydrazyl (DPPH), Linoleic acid (>98\%) and $\beta$-carotene (>95\%) were purchased from Sigma-Aldrich. All the solvents and chemicals (AR grade) are obtained from SD Fine Chemicals, Mumbai, India.

\section{Plant material}

Fresh tubers of Roscoea purpurea were collected in the month of October-November from the nearby area of Kempti fall, Mussoorie, Uttrakhand (India). Tuber sample was authenticated and voucher specimen (LWG no. 254028) was deposited in herbarium repository of CSIRNational Botanical Research Institute. Collected sample was washed, shade dried and powdered for further studies.

\section{Physicochemical characterization}

Various physico chemical values viz. Moisture content, total ash, water soluble ash, acid insoluble ash and extractive values (hexane, alcohol and water soluble extractives) were evaluated. Sample (powder) was also qualitatively screened to indentify the presence of various phytochemicals [7].

\section{Nutritional characterization}

The percentage of various metabolites i.e. oil [7], sugar and starch [8], phenolics [9], flavonoids [10], crude alkaloid [11], total protein [12] and crude fiber [13] present in tubers were determined as per standard procedures.

\section{Extract preparation}

The dried, chopped tubers of $R$. purpurea were grinded using lab grinder and the powder obtained was passed through 40 mesh (up to $500 \mathrm{~mm}$ ) sieve. About $100 \mathrm{~g}$ was defatted with petroleum ether and then treated with methanol (ethanol stabilized) through soxhlation, till complete exhaustion of sample ( 7 days; $27 \pm 2^{\circ} \mathrm{C}$ ). The pooled extracts were filtered through Whatman no. 1 filter paper and concentrated in rotary evaporation at $50^{\circ} \mathrm{C}$ under reduced pressure (40 mbar). The concentrated extracts (RPE) were finally lyophilized and quantified.

\section{Chemical profiling, method optimization, identification and quantification through HPTLC}

Chemical profiling and method optimization for evaluation of polyphenolics was performed on $20 \mathrm{~cm} \times 10 \mathrm{~cm}$ TLC aluminum pre-coated plates with $200 \mathrm{~nm}$ layer thickness of silica gel $60 \mathrm{~F}_{254}$ (sd. Finechem. Ltd, Mumbai, India). Tracks (standard and sample) were applied as $6 \mathrm{~mm}$ band width using Camag 100 micro liter sample syringes (Hamilton, Switzerland) with a Linomat 5 applicator (Camag, Switzerland) under a flow of $\mathrm{N}_{2}$ gas. The Linear ascending development was carried out with Toluene: Ethyl acetate: Formic acid [6:3:1 v/v] as a mobile phase in a Camag glass twin trough chamber. The chamber was previously saturated with mobile phase vapors for $10 \mathrm{~min}$ at room temperature $\left(25 \pm 2^{\circ} \mathrm{C}\right)$ and plates were developed at distance of approximately $80 \mathrm{~mm}$ from the point of application (total length run by mobile phase). After development, plates were dried for $30 \mathrm{~min}$ and scanning was per formed using Camag TLC Scanner 3 at from 200 to $700 \mathrm{~nm}$ in UV absorbance mode for range of flavonoids, operated by win CATS Software (version 3.2.1). The slit dimensions were $4 \mathrm{~mm} \times 0.45 \mathrm{~mm}$ and the scanning speed was $100 \mathrm{~mm} / \mathrm{s}$. Quantification was performed using peak area with linear regression of amount (ng/band). In the employed experimental condition, the HPTLC method includes evaluation of the following performance parameters also such as linearity, Limit of detection, limit of quantification according to the guidelines [14].

\section{Determination of polyphenols}

Total phenolic content was calculated in terms of $\mathrm{mg} / \mathrm{gm}$ GAE (Gallic Acid Equivalent) based on calibration curve of Gallic acid as standard [9] and total flavonoid was 
depicted in terms of mg/gm of QE (Quercetin Equivalent) [10].

\section{Anti oxidant activity}

Ferric reducing power assay

The RPE $(0.2-1.0 \mathrm{mg} / \mathrm{ml})$ in distilled water were mixed with $2.5 \mathrm{~mL}$ of phosphate buffer $(0.2 \mathrm{~mol} / \mathrm{L}, \mathrm{pH} 6.6)$ and $2.5 \mathrm{~mL}$ of $1 \%(\mathrm{w} / \mathrm{v})$ potassium ferricyanide. The mixture was incubated at $50^{\circ} \mathrm{C}$ for $20 \mathrm{~min}$. Following this, $2.5 \mathrm{~mL}$ of $10 \%(\mathrm{w} / \mathrm{v})$ Trichloroacetic acid was added and the mixture was then centrifuged at $800 \mathrm{rpm}$ for $10 \mathrm{~min}$. A $2.5 \mathrm{~mL}$ aliquot of supernatant was mixed with $2.5 \mathrm{~mL}$ of distilled water and $0.5 \mathrm{~mL}$ of $0.1 \%(\mathrm{w} / \mathrm{v}) \mathrm{FeCl}_{3}$; the absorbance of the mixture was read at $700 \mathrm{~nm}$ [15].

\section{$D P P H$ radical scavenging assay}

The effect of RPE on DPPH radical was estimated by using the proposed method [16]. Ascorbic acid, Quercetin, Rutin and BHT were used as reference samples $(0.1 \mathrm{mg} / \mathrm{ml})$ and the ability of standard/RPE to scavenge DPPH radical was calculated by following equation.

DPPH radical scavenging activity(\%)

$$
=\left(\mathrm{Abs}_{\text {control }}-\mathrm{Abs}_{\text {sample }}\right) \times 100 / \mathrm{Abs}_{\text {control }}
$$

where, $\mathrm{Abs}_{\text {control }}$ is the abssorbance of $\mathrm{DPPH}$ radi$\mathrm{cal}+$ methanol and $\mathrm{Abs}_{\text {sample }}$ is the absorbance of DPPH radical $+\mathrm{RPE} /$ standard.

\section{$\beta$-carotene-linoleate assay}

The activity of RPE against $\beta$-carotene-linoleate was estimated without any modification in standard method [17]. The antioxidant activity (AA) of the RPE was evaluated in terms of bleaching of the $\beta$-carotene using the following formula:

$$
\mathrm{AA}(\%)=\left[1-\left(\mathrm{A}^{0}-\mathrm{A}^{\mathrm{t}}\right)\right] \times 100 /\left[1-\left(\mathrm{A}_{0}^{0}-\mathrm{A}_{t}^{t}\right)\right]
$$

where $\mathrm{A}^{0}, \mathrm{~A}_{0}^{0}$ and $\mathrm{A}^{\mathrm{t}}, \mathrm{A}_{\mathrm{t}}^{0}$ are the absorbance values measured at zero time and after incubation for $60 \mathrm{~min}$ in the RPE and control, respectively.

\section{Statistical analysis}

Results were expressed as mean $\pm \mathrm{SD}$. Linear regressions analysis was carried out for standards to calculate total polyphenols content and graph pad prism 5 software was used to calculate the $\mathrm{IC}_{50}$ values. One-way ANOVA followed by student's $t$ test $(\mathrm{p}<0.01)$ was used to find the significance of standard and sample in anti-oxidant activity. Pearson correlation coefficient for phenolic and flavonoids with $\mathrm{IC}_{50}$ value of DPPH and $\beta$-Carotene assays were also employed.

\section{Results}

Estimation of physicochemical and nutritional characters

Moisture content of tuber was $3.22 \%$. Total ash was found to be $5.62 \%$, indicating the presence of in-organic content of the sample, whereas water soluble and acid insoluble ash was 3.95 and $0.30 \%$ respectively. Extractive values by cold maceration of tuber's reveals that water soluble extractive was found to be maximum, followed by alcohol and hexane soluble extractives i.e. 8.66, 6.33 and 5.0\% respectively. These extractive values are primarily useful for determination of exhausted or adulterated drug and was found to be within the limits (Table 1) [6]. Phytochemical screening of powder reveals the presence of carbohydrates, proteins, phenolics, flavonoids, alkaloids, glycosides, tannin and saponins.

Quantification of nutritional content (Table 2) in species reveals that fiber was found to be maximum (28.1\%), followed to oil, protein, alkaloid, starch, phenolics, flavonoids and sugar content i.e. 3.5, 3.46, 2.3, 0.84, 0.71, 0.61 and $0.29 \%$ respectively. Total carbohydrate and gross energy was $82.7 \%$ and $1566.2 \mathrm{~kg} / 100 \mathrm{~g}$ dry matter [18].

\section{Identification and quantification of chemical markers in extract}

Method optimization (Table 3) for chemical profiling of RPE suggested the presence of five major biologically active polyphenolics as protocatechuic acid, syringic

Table 1 Physico chemical values of $R$. purpurea tuber

\begin{tabular}{lc}
\hline Parameter $^{\mathbf{a}}$ & Value (\%) \\
\hline Moisture content & $3.22 \pm 0.01$ \\
Hexane soluble extractive & $5.0 \pm 0.01$ \\
Alcohol soluble extractive & $6.33 \pm 0.005$ \\
Water soluble extractive & $8.66 \pm 0.01$ \\
Total ash & $5.62 \pm 0.01$ \\
Acid insoluble ash & $0.3 \pm 0.005$ \\
Water soluble ash & $3.95 \pm 0.01$ \\
\hline
\end{tabular}

a Values are mean $\pm S D, n=3$.

Table 2 Nutritional characterization of $R$. purpurea tuber

\begin{tabular}{lc}
\hline Nutritional parameters & Values (\%) \\
\hline Sugar & $0.29 \pm 0.01$ \\
Starch & $0.84 \pm 0.01$ \\
Phenolics & $0.71 \pm 0.005$ \\
Flavonoid & $0.6 \pm 0.01$ \\
Protein & $3.46 \pm 0.01$ \\
Alkaloid & $2.3 \pm 0.01$ \\
Oil & $3.5 \pm 0.005$ \\
Fibre & $28.1 \pm 0.01$ \\
\hline
\end{tabular}

Values are mean $\pm S D, n=3$. 
Table 3 Method validation of chemical markers in R. purpurea tubers methanol extract through HPTLC

\begin{tabular}{|c|c|c|c|c|c|}
\hline Parameters & Protocatechuic acid & Vanillic acid & Syringic acid & Kaempferol & Ferullic acid \\
\hline Linearity range (ng) & $100-600$ & $100-600$ & $100-600$ & $100-600$ & $100-600$ \\
\hline Regression coefficient $\left(r^{2}\right)$ & 0.993 & 0.999 & 0.999 & 0.999 & 0.992 \\
\hline LOD (ng) & 35 & 35 & 35 & 35 & 35 \\
\hline LOQ (ng) & 100 & 100 & 100 & 100 & 100 \\
\hline Rf & 0.48 & 0.60 & 0.53 & 0.59 & 0.58 \\
\hline Wavelength (nm) & 305 & 305 & 285 & 305 & 305 \\
\hline
\end{tabular}

(Values are mean, $\mathrm{n}=3$ ).

ng nanogram.

acid, vanillic acid, kaempferol and ferulic acid (Figs. 1, 2). Quantification of secondary metabolites reveals that kaempferol $(0.30 \%)$ was the major metabolite among the other identified markers and then follows the order, vanillic acid $(0.27 \%)$, protocatechuic $(0.14)$, syringic acid $(0.08 \%)$ and ferulic acid $(0.05 \%)$.

\section{Evaluation of anti oxidant potential}

Total phenolic and flavonoid content in RPE was $7.1 \mathrm{mg} / \mathrm{g}$ GAE and $6.1 \mathrm{mg} / \mathrm{g} \mathrm{QE}$ as estimated by regression analysis of Gallic acid and quercetin $(0.1 \mathrm{mg} / \mathrm{ml})$ as standard (Table 4). The reducing power assay of RPE served as significant indicator of its potentiality as reducing agent, which in turns signifies its anti oxidant activity and data (Fig. 3) reveals that reducing power of RPE increases linearly $\left(\mathrm{r}^{2}=0.946\right)$ with increase in concentration, similar to standards i.e. ascorbic acid, quercetin, rutin and BHT respectively. The scavenging effect of DPPH radical was concentration dependant and potentially varied for ascorbic acid, quercetin, rutin and butylated hydroxy toluene (BHT) and RPE (Fig. 4). Ascorbic acid exhibits maximum inhibition of $77.57 \%$ which is followed by quercetin, rutin, RPE and BHT having inhibition of $72.43,71.48,69.57,62.10 \%$ respectively, although the $\mathrm{IC}_{50}$ decreases in order of $\mathrm{RPE}>$ rutin $>$ quercetin $>$ ascorbic acid $>$ BHT and hence indicating that BHT is potent inhibitor of free radical in all (Table 5). Antioxidant activity estimated by bleaching of $\beta$-carotene for standard viz ascorbic acid, quercetin, rutin and BHT (Fig. 5) were estimated. BHT exhibited $\mathrm{IC}_{50}$ at $1.22 \mathrm{mg} /$ $\mathrm{ml}$, thus act as potential anti-oxidant which is followed by quercetin, rutin and RPE (Table 6). Ascorbic acid did not respond to this assay. $\mathrm{IC}_{50}$ of $\mathrm{RPE}$, however was significantly different to that of standards when compared at 5 and $1 \%$ level of significance $(\mathrm{p}<0.01)$ in both DPPH radical scavenging assay and $\beta$-carotene bleaching method. Table 7 reveals that there is positive correlation between $\mathrm{IC}_{50}$ value of $\mathrm{DPPH}$ and $\beta$-carotene beaching method with phenolic and flavonoids content i.e. the antioxidant activity increases linearly with increase in content of phenolics and flavonoids, moreover the values were also significantly $(\mathrm{p}<0.01)$ correlated with each other. Data depicted that correlation is more to flavonoid content (higher $\mathrm{r}^{2}$ value) than to phenolic content.
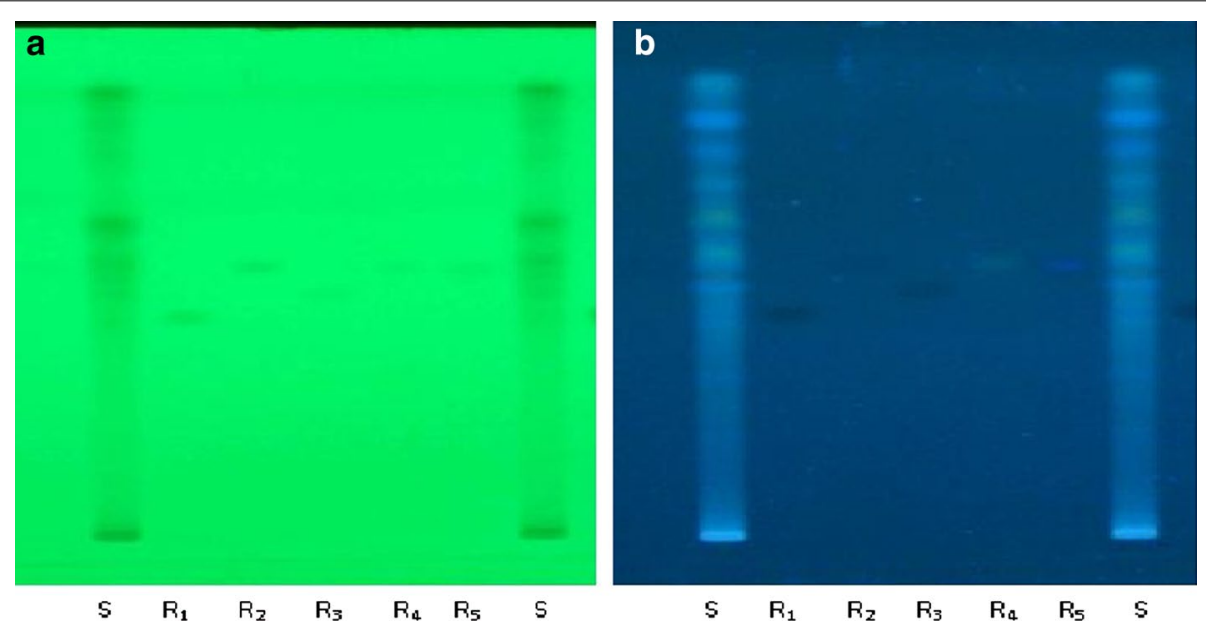

Fig. 1 HPTLC chromatogram of standards ( $R_{1}$ protocatechuic acid, $R_{2}$ vanillic acid, $R_{3}$ syringic acid, $R_{4}$ kaempferol and $R_{5}$ ferulic acid) and sample ( $S$ methanolic extract) at $254 \mathrm{~nm}$ (a) and $365 \mathrm{~nm}$ (b). 


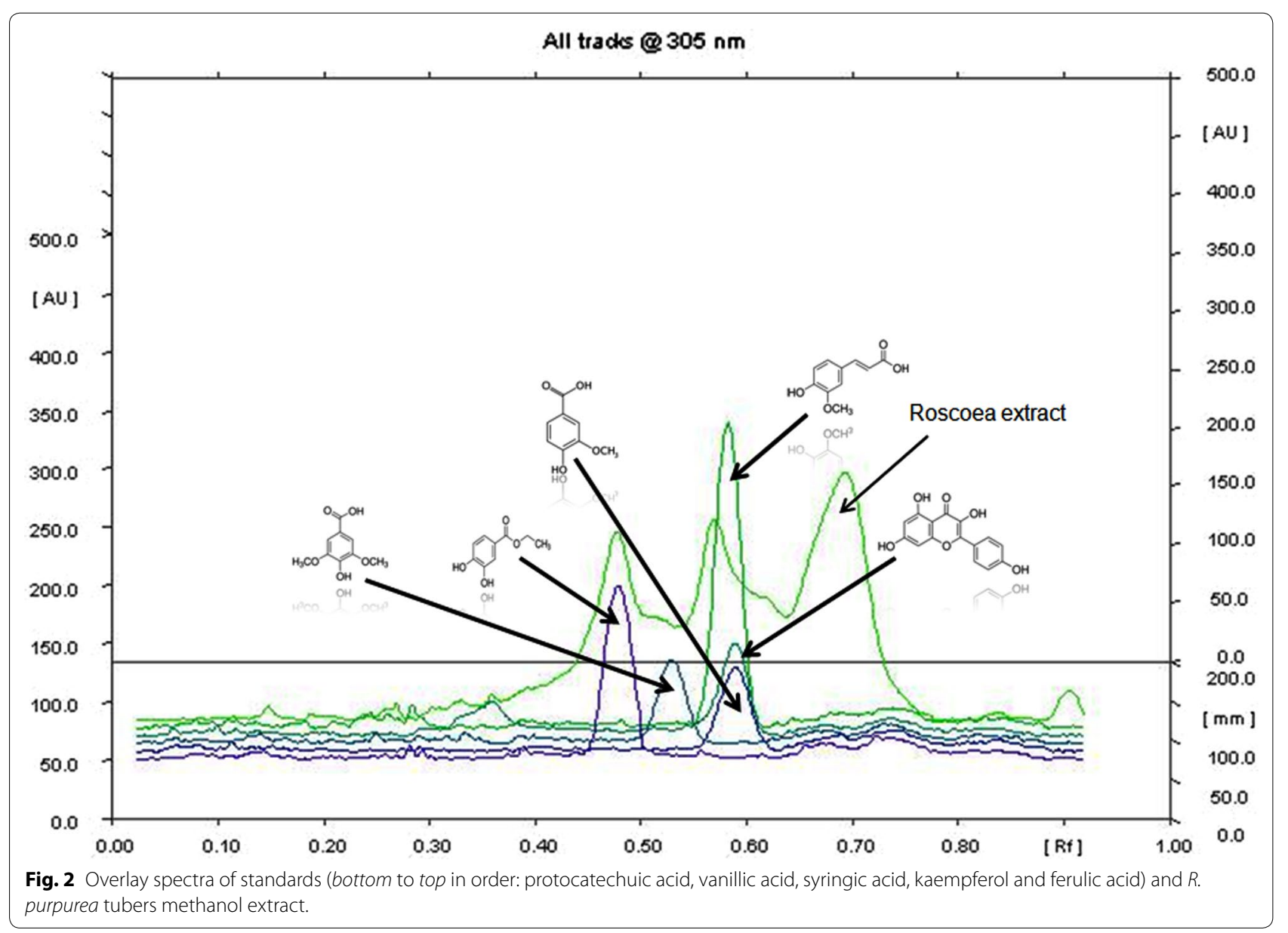

Table 4 Polyphenolics content in methanolic extract of $R$. purpurea tuber

\begin{tabular}{|c|c|c|c|c|}
\hline S. no. & Total poly phenolics ${ }^{b}$ & Values $^{\mathrm{a}}$ & Regression equation $(y)$ & Regression coefficient $\left(r^{2}\right)$ \\
\hline 1. & Total phenolics & $14.13 \pm 0.115$ & $115.9 x+0.113$ & 0.999 \\
\hline 2. & Total flavonoids & $12.23 \pm 0.055$ & $74.61 x+0.058$ & 0.998 \\
\hline
\end{tabular}

a Values are mean $\pm S D(n=3)$.

${ }^{b}$ Total phenolics are represented as $\mathrm{mg}$ Gallic acid/gm of dry weight, total flavonoids are represented as $\mathrm{mg}$ quercetin/gm of dry weight.

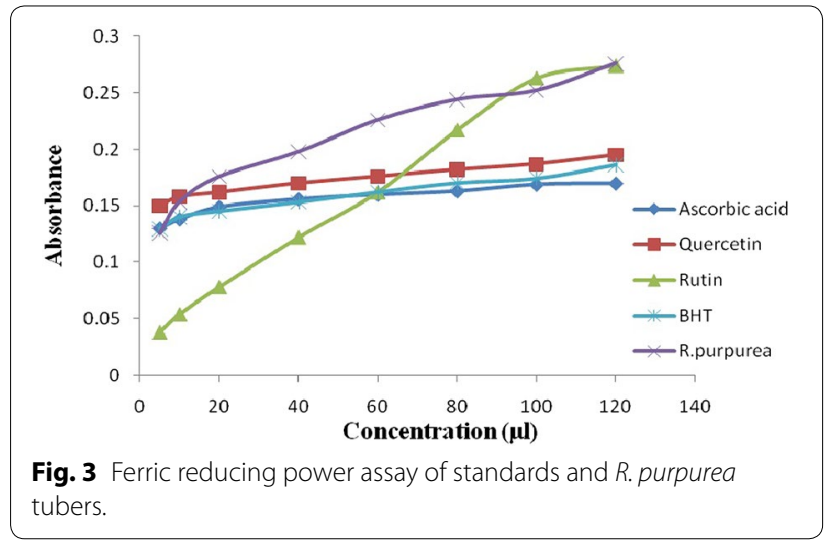

\section{Discussion and conclusions}

The age old edible use of $R$. purpurea tuber has been validated by results of ongoing study, which reveals the presence of wide range of metabolites/phytochemicals of therapeutic use. Physico chemical standards were also established to identify the authentic species among the other closely related members of genus Roscoea. To the best of our knowledge, this is first ever reporting on identification and quantification of chemicals markers (polyphenolics) in $R$. purpurea tuber through HPTLC. The identified markers viz. Protocatechuic acid, syringic acid, vanillic acid, kaempferol and ferulic acid are already well known with validated and potential bioactivities. 


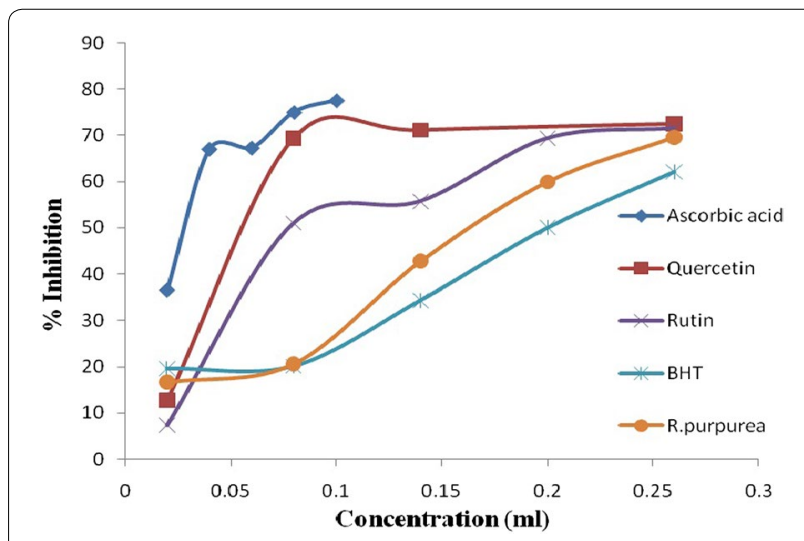

Fig. 4 DPPH radical scavenging activity of standards and R. purpurea tubers.

Table 5 IC $_{50}$ value of standards and $R$. purpurea in DPPH radical scavenging model

\begin{tabular}{llr}
\hline S. no. & Extracts & $\mathbf{I C}_{\mathbf{5 0}}(\boldsymbol{\mu \mathbf { g }} / \mathbf{m l})^{*}$ \\
\hline 1. & Ascorbic acid & $3.86 \pm 0.057$ \\
2. & Quercetin & $5.93 \pm 0.115$ \\
3. & Rutin & $6.8 \pm 0.173$ \\
4. & BHT & $2.06 \pm 0.115$ \\
5. & R. purpurea & $810.66 \pm 1.154$ \\
\hline
\end{tabular}

*Values are mean $\pm S D(n=3)$, indicating significance at $p<0.01$

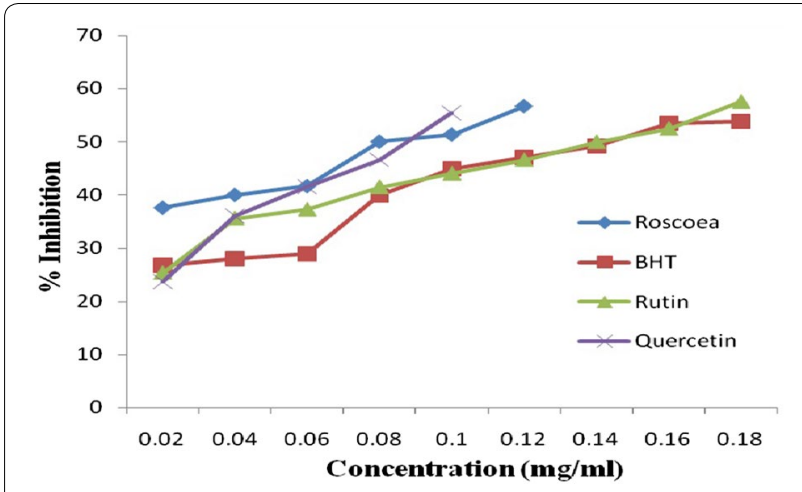

Fig. 5 Antioxidant activity of standards and $R$. purpurea tubers as assessed by $\beta$-carotene.

Table 6 IC $_{50}$ value of standards and $R$. purpurea in $\beta$-carotene bleaching method

\begin{tabular}{llr}
\hline S. no. & Extracts & $\mathbf{I C}_{\mathbf{5 0}}(\boldsymbol{\mu g} / \mathbf{m l})^{*}$ \\
\hline 1. & Quercetin & $8.33 \pm 0.115$ \\
2. & Rutin & $14.06 \pm 0.115$ \\
3. & BHT & $1.22 \pm 0.017$ \\
4. & R.purpurea & $600.66 \pm 1.154$ \\
\hline
\end{tabular}

* Values are mean $\pm S D(n=3)$, indicating significance at $p<0.01$.
Table 7 Correlations between the $I_{50}$ values of $R$. purpurea extract in DPPH, $\beta$-carotene bleaching method and TPC, TFC content

\begin{tabular}{llll}
\hline S. no. & Assay $\left(\mathrm{IC}_{\mathbf{5 0}} \boldsymbol{\mu \mathbf { g } / \mathbf { m l } )}\right.$ & \multicolumn{2}{l}{$\begin{array}{l}\text { Co-relation coefficient } \\
\left(\mathbf{r}^{2}\right)^{*}\end{array}$} \\
\cline { 3 - 4 } & & Phenolics & Flavonoids \\
\hline 1. & DPPH assay & 0.503 & 0.986 \\
2. & $\beta$-carotene bleeching assay & 0.501 & 0.984 \\
\hline
\end{tabular}

* Indicating significance at $p<0.01$.

Polyphenols are the major natural plant inhabiting compounds with anti oxidant activity, which is supposed to be due to their redox potential and thus plays an important role in absorbing, neutralizing, quenching and decomposing the free radical/oxygen and/or superoxide species. Free radical scavenging activity of DPPH is widely used for screening of medicinal plants having anti oxidant activity. The mechanism however, well evident is due to de-colorization of $\mathrm{DPPH}$ by electron donated by anti oxidant compound/moiety and thus stabilizing the DPPH radical. BHT is considered as commercial standard because of its wide use in food grade products as anti-oxidant and hence serves as efficient standard to compare with RPE. On the other hand $\beta$-carotene bleaching method is based on loss of yellow color of $\beta$-carotene, due to its reduction with radicals which are formed by linoleic acid oxidation in emulsion. The rate of bleaching can however be slowed down in presence of anti oxidants and this fact is used in evaluation of anti oxidant activity of extract in comparison with natural and synthetic standards. In spite of the fact that polar compound ascorbic acid is well known antioxidant, it does not respond to $\beta$-carotene bleaching model. This interesting phenomenon is formulated as "polar paradox" and has been reported earlier by several other workers also [19-21] that the polar antioxidants remaining in the aqueous phase of the emulsion are more diluted in lipid phase and are thus less effective in protecting the linoleic acid.

In a conclusion the present studies establish the physicochemical standards of $R$. purpurea which is essential for identification and quality evaluation of one of the main ingredient herb of "Ashtavarga", a polyherbal Ayurvedic formulation. Quantification of metabolites suggested that the tubers are nutritionally rich having appreciable content of fiber $(28.1 \%)$, protein $(3.46 \%)$ and oil (3.5\%). Presence of poly phenolics content viz. TPC $(14.13 \mathrm{mg} / \mathrm{gm}$ GAE) and TFC (12.23 mg/gm QE) was further confirmed by identification and quantification through HPTLC. The anti oxidant potential of $R$. purpurea, as estimated by three models having different mechanism of action suggested the potential activity in species, although $\mathrm{IC}_{50}$ 
varies within assay's. In addition to this, there exists a positive, significant correlation between the phenolic $\left(\mathrm{r}^{2}\right.$ more than 0.500) and flavonoids ( $r^{2}$ more than 0.900) content with the anti oxidant activity of Roscoea extract. This will aid in standardization for quality, purity and sample identification with the presence of various therapeutically/nutritionally active chemical markers along with potential bioactivity. Hence, the study supports the fact that tubers of $R$. purpurea had good nutritional quality with promising antioxidant activity. These results suggested that Roscoea contain biologically/therapeutically active compounds, however to justify these claims we need to do more extensive study based on activity guided fractionation in the future.

\section{Authors' contributions}

AM carried out the physicochemical characterization, Nutritional characterization and antioxidant activity. SS designed the study, collected the plant material, perform statistical analysis and drafting of manuscript, SV perform the chemical profiling of polyphenolic and AKSR coordinated and helped to draft manuscript in its present form. All authors read and approved the final manuscript.

\section{Acknowledgements}

The authors are thankful to the Director CSIR-NBRI for providing facilities and encouragement throughout the work. Thanks to the technical staff for their support. The work is done within the in house project (OLP-089).

\section{Compliance with ethical guidelines}

\section{Competing interests}

The authors declare that they have no competing interests.

Received: 10 December 2014 Accepted: 22 July 2015

Published online: 30 July 2015

\section{References}

1. N Handa Flora of India. http://www.arvindguptatoys.com/arvindgupta/ nimrethanda.pdf. Accessed 16 Oct 2014

2. Singh G, Rawat GS (2011) Ethnomedicinal survey of Kedarnath wildlife sanctuary in Western Himalaya, India. Indian J Fundamen App Life Sci 1(1):35-36

3. Singh AP (2006) Ashtavarga — rare medicinal plants. Ethnobot Leaflets 10:104-108
4. Sahu MS, Mali PY, Waikar SB, Rangari VD (2010) Evaluation of immuno modulatory potential of ethanolic extract of Roscoea procera rhizomes in mice. J Pharm Bioallied Sci 2(4):346-349

5. Bairwa R, Basyal D, Srivastav B (2012) Study of antidiabetic and hypolipidemic activity of Roscoea purpurea (zingiberaceae). Int J Institut Pharm Life Sci 2(4):130-137

6. Chinmay R, Kumari S, Dhar B, Mohanty RC, Dixit R, Padhi MM et al (2011) Pharmacognostical and phytochemical studies of Roscea procera (Kakoli) and Lilium Polyphyllum (Ksheerkakoli) in comparison with market samples. Pharma J 3(25):32-38

7. Anonymous (1996) Indian pharmacopeia, vol II. Government of India: Ministry of health and Family welfare, New Delhi

8. Anonymous (1989) The ayurvedic pharmacopoeia of India, vol 2. Government of India: Ministry of Health and Family Welfare, New Delhi

9. Bray HC, Thorpe WV (1954) Analysis of phenolic compounds of interest in metabolism. Meth Biochem Anal 1:27-52

10. Ordon Ez AAL, Gomez JD, Vattuone MA, Isla MI (2006) Antioxidant activities of Sechium edule (Jacq.) Swart extracts. Food Chem 97:452-458

11. Harborne JB (1973) Phytochemical methods. Chapman and Hall, London

12. Lowry OH, Rosebrough NJ, Farr AL, Randall RJ (1951) Protein measurement with folin phenol reagent. J Bio Chem 193:265-275

13. Mukherjee PK (2008) Quality control of herbal drugs formulation, an approach to evaluation of herbal drug formulations. Galaxy printers, Business Horizons, New Delhi

14. $\mathrm{ICH}$ guidelines Q2R1, Validation of analytical procedures: text methodology, Geneva, Switzerland, November 1996/2005. http://www.ich.org. Accessed 16 Oct 2014

15. Kumaran A, Karunakaran RJ (2007) In vitro antioxidant activities of methanol extract of Phyllanthus species from India. Lebens Wiss Techn 40:344-352

16. Liyana-Pathiranan CM, Shahidi F (2005) Antioxidant activity of commercial soft and hard wheat (Triticum aestivum) as affected by gastric pH conditions. Agric Food Chem 53:2433-2434

17. Adegako GO, Vijay KM, Gopal KAG, Vardaraj MC, Sambaiah K, Lokesh BR (1998) Antioxidants and lipid oxidation in foods. J Food Sci Tech 35:283-288

18. Owolabi AO, Ndidi US, James BD, Amune FA (2012) Proximate, anti nutrient and mineral composition of five varieties of coepea, Vigna unguiculata, commonly consumed in samara community, Zaria-Nigeria. Asian J Food Sci Tech 4(2):70-72

19. Frankel EN, Huang SW, Kanner J, German JB (1994) Interfacial phenomena in the evaluation of antioxidants: bulk oils versus emulsions. J Agri Food Chem 42:1054-1059

20. Koleva II, Van Beek TA, Linssen JPH, De Groot A, Evstatieva LN (2002) Screening of plant extracts for antioxidant activity: a comparative study on three testing methods. Phytochem Anal 13:8-17

21. Porter WL (1993) Paradoxal behaviour of antioxidants in food and biological systems. In: Wiliams GM (ed) Antioxidants, chemical, physiological, nutritional and toxicological aspects. Princeton Scientific, Princeton

\section{Submit your next manuscript to BioMed Central and take full advantage of:}

- Convenient online submission

- Thorough peer review

- No space constraints or color figure charges

- Immediate publication on acceptance

- Inclusion in PubMed, CAS, Scopus and Google Scholar

- Research which is freely available for redistribution

Submit your manuscript at www.biomedcentral.com/submit

C BioMed Central 